\title{
Association between the GHR, GHRHR, and IGF1 gene polymorphisms and milk yield and quality traits in Sarda sheep
}

\author{
Maria L. Dettori, ${ }^{*}$ Michele Pazzola, ${ }^{* 1}$ Pietro Paschino, ${ }^{*}$ Marcel Amills, $†$ and Giuseppe M. Vacca* \\ *Department of Veterinary Medicine, University of Sassari, Via Vienna 2, 07100 Sassari, Italy \\ †Department of Animal Genetics, Centre for Research in Agricultural Genomics (CSIC-IRTA-UAB-UB), \\ Campus Universitat Autònoma de Barcelona, Bellaterra 08193, Spain
}

\section{ABSTRACT}

The growth hormone receptor $(G H R)$, the growth hormone releasing hormone receptor $(G H R H R)$, and the insulin-like growth factor 1 (IGF1) genes are known to modulate growth, reproduction, and lactation traits in livestock. The aim of the current work was to investigate if the variation of the sheep GHR, GHRHR, and IGF1 genes is associated with milk yield and quality traits. Three hundred eighty dairy Sarda sheep were genotyped for 36 single nucleotide polymorphisms (SNP) mapping to these 3 loci, and records for milk yield and daily fat and protein yield, as well as for fat, protein, casein, lactose, and milk urea contents, $\mathrm{pH}$, somatic cell score, logarithmic bacterial count, and milk energy were obtained. The linkage disequilibrium analysis was performed only for $G H R$, as both GHRHR and $I G F 1$ had only 1 polymorphic SNP. Haplotype analysis revealed the existence of 7 haplotype blocks in GHR. Two haplotype blocks, including part of the intron 1 and the upstream region, were clearly separated from the remaining 5 blocks by SNP rs412986330, which may be a recombination hotspot. The latter 5 blocks were contiguous, spanning from intron 2 to exon 10. Statistical analysis revealed that the GHR polymorphism is significantly associated with milk traits for daily fat and protein yield and fat, milk urea, and lactose content. Moreover, variation in $I G F 1$ was associated with milk protein and casein content. Data generated in this research provide new insights into the allelic effects of the ovine GHRHR, GHR, and IGF1 genes on milk production and quality traits, information that may be useful in gene-assisted selection programs.

Key words: growth hormone receptor, single nucleotide polymorphism, haplotypes, association analysis, sheep milk

Received April 12, 2018.

Accepted July 1, 2018.

${ }^{1}$ Corresponding author: pazzola@uniss.it

\section{INTRODUCTION}

In the Mediterranean basin, sheep milk contributes appreciably to the production of many different cheese varieties that differ in texture, color and flavor. With more than 3 million Sarda sheep, Sardinia is one of the main ovine milk providers in southern Europe (Bittante et al., 2017).

The economic importance of sheep milk production has led to investigations of which genomic regions influence ovine growth and dairy traits (Chessa et al., 2017). Three molecules integrated in the somatotropic axis and linked by a complex regulation (Akers, 2002) could have a major role in milk production: growth hormone receptor (GHR), growth hormone-releasing hormone receptor (GHRHR), and IGF-1.

The GHR is a regulator of postnatal growth and, as the growth hormone, it has important effects on carbohydrate, protein, and lipid metabolism. The GHR is a type I cytokine receptor that forms part of the Janus kinase $(\mathrm{JAK}) /$ signal transducers and activators of transcription (STAT) signaling pathways, and it has an extracellular and an intracellular domain. In humans, it is organized as a constitutive dimer, being activated by the binding of the growth hormone monomer (Brooks et al., 2008). The sheep growth hormone receptor is encoded by the GHR gene, which maps to Oar16:31 .8-32.0 Mb (ovine reference genome Oar_v3.1; https: //www.ncbi.nlm.nih.gov/assembly/GCF_000298735 $.1 /$ ) and spans $167.5 \mathrm{~kb}$. The GHR gene includes 10 exons, and encodes a transmembrane receptor protein of 651 AA residues. In cattle, mutations in GHR have been associated with growth and meat quality traits (Di Stasio et al., 2005). A missense variant (F279Y) located in exon 8 of the bovine $G H R$ gene has been associated with milk yield and composition in Ayrshire, Holstein, and Jersey cattle (Blott et al., 2003) as well as with protein percentage and fat percentage (Viitala et al., 2006) and milk yield and BCS (Banos et al., 2008). Pegolo et al. (2016) demonstrated that the GHR polymorphism is associated with milk fatty acid composition in dairy cows. In goats, a variable thymine-guanine 
repeat in GHR did not display significant associations with dairy traits such as milk yield or composition and SCC (Maj et al., 2007). In addition, the variation of the ovine GHR gene was not associated with milk traits in Churra sheep (García-Fernández et al., 2011). By using a genome-wide association study methodology to search for candidate regions targeted by selection, Wang et al. (2015) identified GHR as a growth-related gene, potentially affecting meat production and quality, as well as reproduction traits, in the German Mutton Merino sheep breed. Bolormaa et al. (2016) included the ovine $G H R$ gene in a group of loci with pleiotropic effects on body composition in meat breeds, but little is known about the effect of GHR polymorphisms on sheep dairy traits.

The GHRHR protein is a G-protein-coupled receptor with 7 transmembrane domains and it is expressed specifically in somatotropic cells. The activation of GHRHR in response to growth hormone-releasing hormone binding leads to the release of growth hormone stored in secretory granules and stimulates de novo GH production in somatotropes (Pang and Chan, 2010). The sheep GHRHR gene maps to chromosome Oar4: 65.35-65.36 Mb (Oar_v3.1) and includes 14 exons encoding a 426-AA long protein.

The IGF-1 polypeptide hormone is the major mediator of prenatal and postnatal growth (Baker et al., 1993). It is produced in many tissues, but mainly in the liver in response to growth hormone stimulation, and it behaves as an endocrine, paracrine, and autocrine hormone in peripheral tissues (Pang and Chan, 2010). The sheep IGF1 gene maps to chromosome 3:171,26-171,32 $\mathrm{Mb}$ (reverse strand); it spans $59.3 \mathrm{~kb}$ and it encompasses 5 exons encoding a 172-AA long protein.

Association studies concerning the association of the polymorphism of these 3 genes with ovine dairy traits are scarce, especially with regard to the Sarda breed, which has a great economic value due to its excellent dairy performance. The main goal of our study was to investigate if the polymorphism of the ovine $G H R$, GHRHR, and IGF1 genes are associated with milk traits in Sarda sheep.

\section{MATERIALS AND METHODS}

\section{Animals and Sampling}

The resource population included 380 ewes sampled from 19 different farms (20 ewes/farm) located in Sardinia (Italy). All the ewes were officially registered in the Sarda breed flock book and they were included in the selection scheme of the Sarda breed. Farms, animals, and sampling have been reported in Pazzola et al. (2014) and Vacca et al. (2015). Briefly, ewe parity ranged from
1 (primiparous) to 9 , and ewes were sampled between 2 and 7 mo after parturition. Each of the 380 ewes was sampled just 1 time (single-day sampling) to obtain an individual milk sample per ewe at each farm. Samples were collected during the afternoon milking in 200-mL sterile plastic containers. Daily milk yield was recorded as the morning plus evening milking. A blood sample was taken from each ewe in $\mathrm{K}_{3}$ EDTA vacuum tubes (BD Vacutainer, Becton Dickinson, Franklin Lakes, NJ). Genomic DNA was isolated with the Gentra Puregene Blood Kit (Qiagen, Hilden, Germany) and purity and concentration were measured with an Eppendorf BioPhotometer instrument (Eppendorf, Hamburg, Germany). Once collected, milk samples were kept at $4^{\circ} \mathrm{C}$ and analyzed within $24 \mathrm{~h}$. Milk fat, protein, casein, lactose, and milk urea (MU) content and $\mathrm{pH}$ were measured with a MilkoScan FT6000 device (Foss Electric, Hillerød, Denmark), according to the International Dairy Federation (IDF) standard 141:2013 (ISO-IDF, 2013); daily fat and protein yield (dFPY; measured in $\mathrm{g} / \mathrm{d}$ ) was calculated as the sum of fat and protein content in relation to daily milk yield. Total bacterial count (TBC) was determined with a BactoScan FC150 instrument (Foss Electric) and transformed to log-bacterial count to normalize the distribution of the measurements [log-bacterial count $=\log _{10}$ (total bacterial count $/ 1,000)$ ]. Somatic cell count was determined with a Fossomatic 5000 equipment (Foss Electric) according to the IDF 148-2:2006 method (ISO-IDF, 2006) and then transformed into the logarithm score $\left[\mathrm{SCS}=\log _{2}\right.$ $\left.\left(\mathrm{SCC} \times 10^{-5}\right)+3\right]$.

\section{Design of a TaqMan Real-Time PCR Assay}

A custom TaqMan Real-Time PCR assay (Thermo Fisher Scientific, Waltham, MA) was designed for SNP genotyping. It included a total of 31 SNP mapping to the sheep GHR gene. The GHR SNP were retrieved from the Ensembl Genome database (http://www .ensembl.org/Ovis_aries/Gene/Variation_Gene/Table $? \mathrm{db}=\mathrm{core} ; \mathrm{g}=$ ENSOARG00000008837; $\mathrm{r}=16: 31829583$ $-32003795 ; \mathrm{t}=$ ENSOART00000009622). Moreover, 2 and 3 SNP mapping to the GHRHR and IGF1, respectively, were retrieved from the dbSNP database (https://www .ncbi.nlm.nih.gov/projects/SNP/) and genotyped in the 380 Sarda sheep. Sequences flanking the SNP are given in Supplemental Table S1 (https://doi.org/10 $.3168 /$ jds.2018-14914) and the full panel of $36 \mathrm{SNP}$ is reported in Table 1. Each SNP plus 60-bp flanking sequences were submitted to the Custom TaqMan Assay Design Tool web page (https://www.thermofisher.com/ order/custom-genomic-products/tools/genotyping/) to design an assay matching the producer's criteria. Genotyping was carried out in the Servei Veterinari de 
Table 1. Description of the markers mapping to the GHR, GHRHR and IGF1 genes and associated population parameters in Sarda sheep

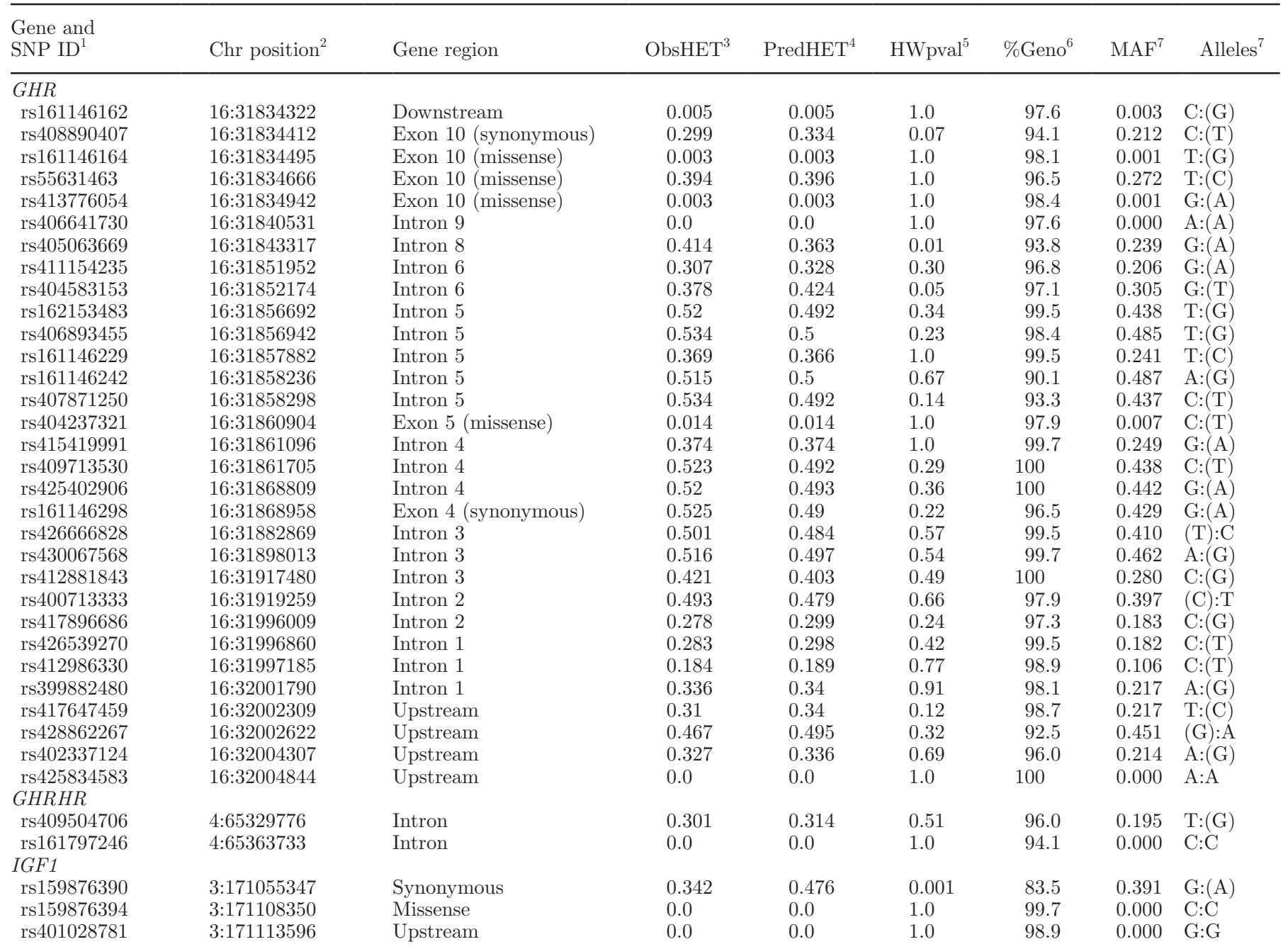

${ }^{1} \mathrm{SNP}$ ID $=$ dbSNP reference records (https://www.ncbi.nlm.nih.gov/projects/SNP/).

${ }^{2} \mathrm{Chr}$ position $=$ chromosome position on Oar_v4.0 (https://www.ncbi.nlm.nih.gov/assembly/GCF_000298735.2/).

${ }^{3}$ ObsHET $=$ observed heterozygosity.

${ }^{4}$ PredHET $=$ predicted heterozygosity.

${ }^{5} \mathrm{HWpval}=$ Hardy-Weinberg test $P$-value.

${ }^{6} \% \mathrm{Geno}=$ percentage of genotyped samples.

${ }^{7} \mathrm{MAF}=$ minor allele frequency (minor allele in brackets).

Genetica Molecular from the Universitat Autonoma de Barcelona (http://sct.uab.cat/svgm/en) by using a 12K Flex QuantStudio instrument (Thermo Fisher Scientific). Genotypes were visualized with the Taqman Genotyper v.1.3 software (Applied Biosystems, Foster City, CA), and SNP with call rates $<0.9$ were removed from the data set.

\section{Haplotype and Statistical Analyses}

The Haploview software package (Barrett et al., 2005) was used to estimate and plot pairwise linkage disequilibrium (LD) measures [normalized coefficient of linkage disequilibrium $\left(\mathbf{D}^{\prime}\right)$ and squared correlation $\left(\mathrm{r}^{2}\right)$ ]. The same tool was used to infer haplotype frequencies and to define LD blocks according to the Gabriel criteria (Gabriel et al., 2002). Haplotypes can be defined as specific combinations of alleles in a genomic DNA region. On the other hand, a haplotype block is a DNA region where no recombination has occurred in the ancestors of that population. Gabriel et al. (2002) identified haplotype blocks by examining the recombination patterns across each region on the basis of information provided by markers with minor 
allele frequency $>1 \%$. This measure is based on the value of the allelic association $\mathrm{D}^{\prime}$ normalized (Daly et al., 2001). As Gabriel et al. (2002) rely on confidence bounds on $\mathrm{D}^{\prime}$, the one-sided upper $95 \%$ confidence bound for strong LD was set to $>0.98$ (indicating no historical recombination). In contrast, a pair of markers was considered strong evidence of historical recombination when the upper confidence bound on $\mathrm{D}^{\prime}$ was less than 0.9 (Gabriel et al., 2002) Haploview was also used to estimate minor allele frequencies (MAF), observed and expected heterozygosity, and to identify significant departures from the Hardy-Weinberg equilibrium at each polymorphic locus.

Association analysis between GHR, GHRHR, and IGF1 genotypes and milk traits was based on the model

$$
\begin{aligned}
\mathrm{Y}= & \mu+\mathrm{G}+\mathrm{F}+\mathrm{P}+\mathrm{DIM} \\
& +\operatorname{SIRE}(\mathrm{G})+\mathrm{e}_{\mathrm{ijklmn}},
\end{aligned}
$$

where $\mathrm{Y}$ is the observed trait; $\mu$ is the general mean; $\mathrm{G}$ is the fixed effect of the SNP genotype, one at a time (2 to 3 levels: the 2 homozygotes and the heterozygote); $\mathrm{F}$ is the fixed effect of the farm, which also includes animal management and feeding (1 to 19 levels; the different farms where animals were reared); $\mathrm{P}$ is the fixed effect of parity of the ewes ( 1 to 4 levels; first to fourth or more parities); DIM is the fixed effect of the days in milking ( 4 levels; $1=\leq 100 \mathrm{~d} ; 2=101-140 \mathrm{~d}$; $3=141-160 \mathrm{~d} ; 4=\geq 161 \mathrm{~d}) ; \operatorname{SIRE}(\mathrm{G})$ is the random effect of the sire (101 different sires) nested within the genotype; and $\mathrm{e}_{\mathrm{ijk} k \mathrm{mn}}$ is the random residual effect.

The same model expressed in equation [1] was used to investigate the association between milk traits and each of the $7 \mathrm{LD}$ blocks, one at a time. In the single SNP and LD block analysis we only considered SNP with a MAF $>0.050$ to make sure that genotypic means were correctly estimated. The MIXED procedure of SAS (version 9.4, SAS Institute Inc., Cary, NC) was used to carry out the association analysis and correction for multiple testing was implemented with the Bonferroni method (one milk trait for each SNP or LD block at a time). Model effects were significant at $P<0.05$.

\section{RESULTS}

\section{Allele Frequencies of the GHR, GHRHR, and IGF1 Polymorphisms in Sarda Sheep}

The description of the 36 analyzed SNP and the associated population parameters is provided in Table 1. The ovine GHR gene is about $167 \mathrm{kbp}$ long and $98.8 \%$ of this gene is made of intronic regions. Many variants have been reported for this gene, out of which 3,038 are intronic variants, 14 missense and 9 synonymous (Ensembl, https://www.ensembl.org/index.html). Among these variants, we chose a panel of 31 SNP spanning the entire gene sequence and genotyped 380 dairy Sarda breed ewes. A total of 6 exonic GHR SNP were analyzed and rs161146164 and rs413776054 (both missense variants located in exon 10) and rs404237321 (a missense variant localized in exon 5) markers showed MAF lower than 5\%, whereas rs408890407 (exon 10, synonymous), rs55631463 (exon 10, missense), and rs161146298 (exon 4, synonymous) showed MAF higher than 5\%. According to the SIFT (http://sift.jcvi.org/ ) prediction algorithm, none of the variants were expected to affect protein function. All intronic SNP were polymorphic in the analyzed population and showed MAF higher than 5\%, except rs406641730 (intron 9), which was monomorphic. The only downstream variant analyzed in $G H R$ was rare (MAF $=0.003)$, and 1 of the 4 upstream variants was monomorphic (rs425834583). For GHRHR, 1 of the 2 genotyped SNP was monomorphic, and in IGF1 2 of the 3 SNP analyzed were monomorphic. Genotype distributions were in HardyWeinberg equilibrium, except for rs405063669 (intron 8, GHR) and rs159876390 (IGF1).

\section{Effect of GHR, GHRHR, and IGF1 Genotypes on Dairy Traits}

Descriptive statistics of daily milk yield and quality traits recorded in the Sarda sheep are displayed in Table 2. Phenotypes showing the highest variability were daily milk yield and dFPY, with coefficients of variation (CV) above $50 \%$. The CV of MU (35\%), LBC (36\%), and SCS (46\%) were also considerably high. The results of the ANOVA ( $F$-values) of daily milk yield and quality traits versus $G H R, G H R H R$, and IGF1 genotypes are reported in Supplemental Table S2 (https://doi.org/10.3168/jds.2018-14914). Markers displaying significant effects on phenotype variance are described in detail in Supplemental Table S3 (https:// doi.org/10.3168/jds.2018-14914).

In GHR, the rs55631463 SNP marker was associated with dFPY $(P<0.05)$ and homozygote CC ewes displayed the highest genotypic mean $(227.4 \mathrm{~g} / \mathrm{d}$, with $\mathrm{SE}$ of 11.07). Moreover, the rs404583153 SNP (intron 6) was significantly associated with SCS $(P<0.05)$. In the upstream region of $G H R$, the rs417647459 marker was significantly associated with lactose content $(P<0.05)$, and homozygote $\mathrm{CC}$ ewes showed the highest genotypic mean (4.94\%, with SE of 0.06). The rs399882480, rs428862267 $(P<0.05)$, and $402337124(P<0.01)$ SNP were associated with MU. With regard to IGF1, 
Table 2. Descriptive statistics for milk daily yield and quality traits in Sarda sheep

\begin{tabular}{|c|c|c|c|c|c|c|}
\hline \multirow[b]{2}{*}{ Trait } & \multirow[b]{2}{*}{$\mathrm{N}$} & \multirow[b]{2}{*}{ Mean } & \multirow[b]{2}{*}{ SD } & \multirow[b]{2}{*}{$\mathrm{CV}(\%)$} & \multicolumn{2}{|c|}{ Percentile } \\
\hline & & & & & $\mathrm{P} 1$ & P99 \\
\hline \multicolumn{7}{|l|}{ Daily yield traits, $\mathrm{g} / \mathrm{d}$} \\
\hline Milk yield (dMY) & 376 & 1641.3 & 899.2 & 55 & 200.0 & 4176.0 \\
\hline Fat and protein yield (dFPY) & 376 & 192.8 & 102.9 & 53 & 23.6 & 452.0 \\
\hline \multicolumn{7}{|l|}{ Milk quality traits } \\
\hline Fat, $\%$ & 376 & 6.50 & 1.23 & 19 & 4.13 & 10.41 \\
\hline Protein, \% & 376 & 5.46 & 0.72 & 13 & 4.29 & 7.50 \\
\hline Casein, \% & 376 & 4.27 & 0.61 & 14 & 3.25 & 5.96 \\
\hline Lactose, \% & 376 & 4.81 & 0.28 & 6 & 4.03 & 5.36 \\
\hline Milk urea, mg/dL & 375 & 32.9 & 11.4 & 35 & 10.70 & 59.90 \\
\hline $\mathrm{pH}$ & 316 & 6.66 & 0.09 & 1 & 6.50 & 6.86 \\
\hline $\mathrm{SCS}^{1}$ & 376 & 4.72 & 2.18 & 46 & 0.75 & 10.31 \\
\hline $\mathrm{LBC}^{2}$ & 355 & 2.54 & 0.93 & 36 & 0.78 & 4.23 \\
\hline Milk energy, MJ $/ \mathrm{kg}$ & 376 & 4.63 & 0.58 & 13 & 3.56 & 6.34 \\
\hline
\end{tabular}

${ }^{1} \mathrm{SCS}=\log _{2}\left(\mathrm{SCC} \times 10^{-5}\right)+3$.

${ }^{2}$ Logarithmic bacterial count $(\mathrm{LBC})=\log _{10}($ total bacterial count $/ 1,000)$.

the rs159876390 SNP was associated with milk protein and casein contents $(P<0.05)$, and homozygote AA ewes displayed the highest genotypic means for protein (5.76\%, with SE of 0.12 ) and casein (4.51\%, with SE of 0.10$)$.

\section{LD Analysis and Haplotype Effect}

The results of LD analysis made with the Haploview software are shown in Figures 1 and 2. Linkage disequilibrium analysis was performed only for $G H R$, as both GHRHR and IGF1 loci had only 1 segregating SNP. To determine the haplotype structure of the sheep GHR gene, SNP rs406641730 and rs425834583 were excluded because they were monomorphic. The resulting set of $29 \mathrm{SNP}$ covered about $169.9 \mathrm{~kb}$ and the average distance between SNP was $6.07 \mathrm{~kb}$, ranging from 62 to $76.7 \mathrm{~kb}$. Seven regions of LD were identified in GHR, the larger (block 4) covered $61 \mathrm{~kb}$, spanning introns 2 to 5 , followed by block 1 (the second in size), which covered $8 \mathrm{~kb}$ from intron 8 to exon 10. Haplotype block 2 included 2 SNP, both localized on intron 6 , only 67 bp away from exon 7 . The 3 SNP included in haplotype block 3 were all localized in intron 5, 106 bp upstream of exon 6 . Two different haplotype blocks were identified in the upstream region of GHR: block 7 , including 2 SNP, and block 6, spanning from intron 1 to the upstream region. Haplotype blocks 6 and 7 were adjacent to each other and clearly separated from the remaining 5 blocks by SNP rs412986330. This SNP, which is located at intron 1 , physically close to block 6 , might be a recombination hotspot. Haplotype block 5 had 2 SNP positioned upstream (rs426539270, intron 1) and downstream (rs417896686, intron 2) of exon 2 , forming a haplotype block including exon 2 .
Block 4, the largest in size, consisted of 10 SNP. It had 7 possible haplotype combinations, and it could be captured by 6 different haplotype tagging SNP (htSNP). Blocks 1 and 3 included 3 SNP and were defined by 4 different haplotype combinations, being tagged by each of the 3 SNP (3 htSNP). Blocks 2, 5, 6 , and 7 included 2 SNP and had 2 (block 5) or 3 different haplotype combinations, with 1 htSNP (block 5 ) or $2 \mathrm{htSNP}$. Haplotype association analysis (Table 3) revealed a significant effect of block 1 on milk fat content and energy $(P<0.05)$, with the lowest values recorded for haplotype $\mathrm{H} 4$ (CCG), and on the casein content, with the highest values featured by haplotype H3 (TTG). Block 5 was significantly associated with milk energy $(P<0.05)$, and haplotype H1 $(\mathrm{CC})$ was showed the highest values.

\section{DISCUSSION}

The GHR gene plays a fundamental role in the neuroendocrine control of milk synthesis by regulating carbohydrate, protein, and lipid metabolism. Several studies have highlighted $G H R$ as a candidate locus for dairy traits in cattle (Blott et al., 2003; Viitala et al., 2006; Pegolo et al., 2016). For this reason, we hypothesized that variations of the ovine GHR gene might affect milk quality traits in Sarda sheep. Our investigation highlighted the existence of a significant association between the rs55631463 GHR SNP genotype and milk dFPY, with the CC genotype displaying the highest genotypic mean $(227.4 \mathrm{~g} / \mathrm{d})$. We are also aware that for genotypes with low frequencies, as in the case of CC homozygotes at rs55631463, represented by 28 ewes, the model used for the statistical analysis may lead to large errors, as evidenced by the high values of 


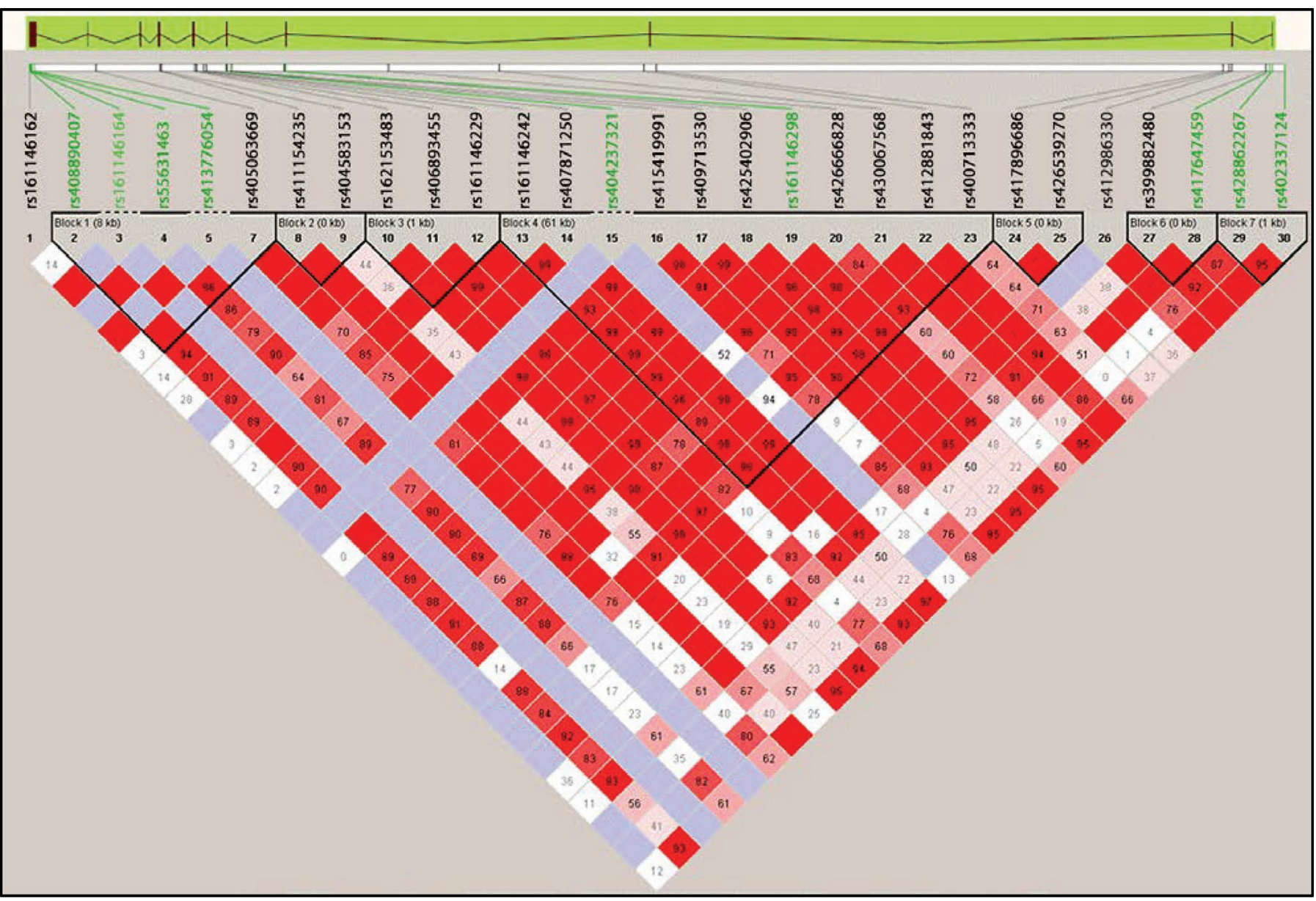

Figure 1. Linkage disequilibrium structure of the GHR gene in Sarda sheep. Structural organization of the GHR gene, retrieved from Ensembl (https://www.ensembl.org/index.html), with exons represented by boxes and introns by horizontal lines. The first box on the left corresponds to exon 10 and the first on the right is exon 1, as the GHR gene sequence is on the reverse strand of chromosome 16. Haploview plot of pairwise normalized coefficient of linkage disequilibrium $\left(\mathrm{D}^{\prime}\right)$ : red (dark gray), $\mathrm{D}^{\prime}=1.0$ and logarithm of the odds $(\mathrm{LOD}) \geq 2.0$; blue (light gray), $\mathrm{D}^{\prime}=1.0$ and $\mathrm{LOD}<2.0$; white, $\mathrm{D}^{\prime}<1.0$ and $\mathrm{LOD}<2.0$. Linkage disequilibrium blocks are defined by a black line; SNP in black are within intron regions, whereas SNP in green (gray) are exonic or located in the upstream regions (SNP 28, 29, and 30). Color version available online.

standard error of least squares means (Supplemental Table S3; https://doi.org/10.3168/jds.2018-14914).

Crisà et al. (2010) genotyped SNP rs55631463 in 3 Italian sheep breeds, including 34 Sarda breed ewes, and found that, overall, in the 3 breeds, the $\mathrm{C}$ allele was associated with decreased milk fat content $(-14 \%)$. Nonetheless, if we take into account the haplotype analysis, it is evident that the $\mathrm{C}$ allele of SNP rs55631463 is associated with a decrease in fat content when included in haplotype CCG (H4) of block 1. In contrast, in the CCA (H2) haplotype the $\mathrm{C}$ allele is associated with higher fat, protein, and energy contents. In summary, the association of the $\mathrm{C}$ genotype of the rs55631463 SNP depends on the specific haplotype under consideration as well as on its frequency in the resource population. This can be related to the role of growth hormone-GHR, as well as the GHR effector system linkages within the cell, on lipid metabolism. Specifically, growth hormone-GHR stimulate lipolysis by modulating gene expression and protein activation. The mobilization of lipids from adipose tissue increases the plasma free fatty acids and their utilization by cells of other tissues (Bergan-Roller and Sheridan, 2018). The growth hormone is the only endogenous ligand of GHR (Bergan-Roller and Sheridan, 2018), and association studies with dairy traits showed that polymorphism of the $G H$ gene affected milk yield in Serra da Estrela ewes (Marques et al., 2006) and Sarda ewes (Vacca et al., 2013) as well as milk fat content in Sarda ewes (Dettori et al., 2015).

The SNP rs417647459 and rs411154235 were associated with milk lactose content (Supplemental Table S3; 
Table 3. Least squares means (and SE between brackets) of milk traits according to the different haplotype blocks in Sarda sheep

\begin{tabular}{|c|c|c|c|c|c|c|}
\hline Block & Haplotype (H) & $\mathrm{H}$ & $\mathrm{n}$ & Fat, $\%$ & Casein, $\%$ & Milk energy, MJ/kg \\
\hline \multirow[t]{4}{*}{ Block 1} & CTG & $\mathrm{H} 1$ & 80 & $6.51^{\mathrm{a}}$ & $4.20^{\mathrm{ab}}$ & $4.61^{\mathrm{a}}$ \\
\hline & $\mathrm{CCA}$ & $\mathrm{H} 2$ & 11 & $\begin{array}{c}(0.12) \\
6.55^{\mathrm{a}} \\
(0.29)\end{array}$ & $\begin{array}{c}(0.06) \\
4.21^{\mathrm{ab}} \\
(0.15)\end{array}$ & $\begin{array}{c}(0.06) \\
4.62^{\mathrm{a}} \\
(0.14)\end{array}$ \\
\hline & TTG & H3 & 20 & $6.67^{\mathrm{a}}$ & $4.40^{\mathrm{a}}$ & $4.74^{\mathrm{a}}$ \\
\hline & $\mathrm{CCG}$ & $\mathrm{H} 4$ & 4 & $\begin{array}{c}(0.22) \\
3.36^{\mathrm{b}} \\
(0.95)\end{array}$ & $\begin{array}{c}(0.11) \\
2.89^{b} \\
(0.50)\end{array}$ & $\begin{array}{c}(0.10) \\
3.05^{\mathrm{b}} \\
(0.45)\end{array}$ \\
\hline \multirow[t]{2}{*}{ Block 5} & $\mathrm{CC}$ & H1 & 246 & $\begin{array}{c}6.49 \\
(0.08)\end{array}$ & $\begin{array}{c}4.24 \\
(0.04)\end{array}$ & $\begin{array}{r}4.61^{\mathrm{a}} \\
(0.04)\end{array}$ \\
\hline & GT & $\mathrm{H} 2$ & 15 & $\begin{array}{c}5.95 \\
(0.27)\end{array}$ & $\begin{array}{c}3.97 \\
(0.13)\end{array}$ & $\begin{array}{r}4.33^{\mathrm{b}} \\
(0.12)\end{array}$ \\
\hline
\end{tabular}

$\overline{\mathrm{a}, \mathrm{b}}$ Means with different superscript lowercase letters in each column differ significantly in genotype comparison at $P<0.05$.

https://doi.org/10.3168/jds.2018-14914). This finding can be related to the role of the growth hormoneGHR axis on carbohydrate metabolism, as lactose is synthesized in the mammary gland from galactose and glucose (Brew and Hill, 1975). The growth hormoneGHR system acts on glucose metabolism as an insulin antagonist; it facilitates the transformation of glucose into glycogen up to the saturation of glycogen cellular deposits. At the same time, it depresses glycolysis, leading to an increase in glycemia (Kim and Park, 2017).

The association of SNP located in the $5^{\prime}$ region (upstream and intron 1) of GHR on MU content might be linked to the effect of this hormone on protein metabolism. The growth hormone-GHR system exerts an anabolic action, as it promotes AA uptake, RNA synthesis, and protein synthesis (Sheridan, 2011). Moreover, in humans it reduces protein catabolism and decreases deamination of AA and hepatic urea formation (Møller and Jørgensen, 2009). Urea is synthesized in the liver from ammonia generated by the catabolism of proteins and AA absorption. In ruminants, the excess of ammonia is absorbed through the rumen wall, being transformed into urea and excreted in urine and milk (Roy et al., 2011).

The metabolic action of growth hormone-GHR occurs on multiple tissues and can be directly or indirectly mediated by IGF. Plasma growth hormone stimulates the secretion of IGF-1 from the liver, and IGF-1 stimulates cell growth and differentiation in target tissues by utilizing specific receptors (Bergan-Roller and Sheridan, 2018). The IGF1 SNP genotyped in Sarda sheep (rs159876390) was associated with protein and casein contents $(P<0.05)$. This result was not described in previous reports, where attention was more focused on growth-related traits (Grochowska et al., 2017) and reproduction traits (He et al., 2012). Crisà et al. (2010)

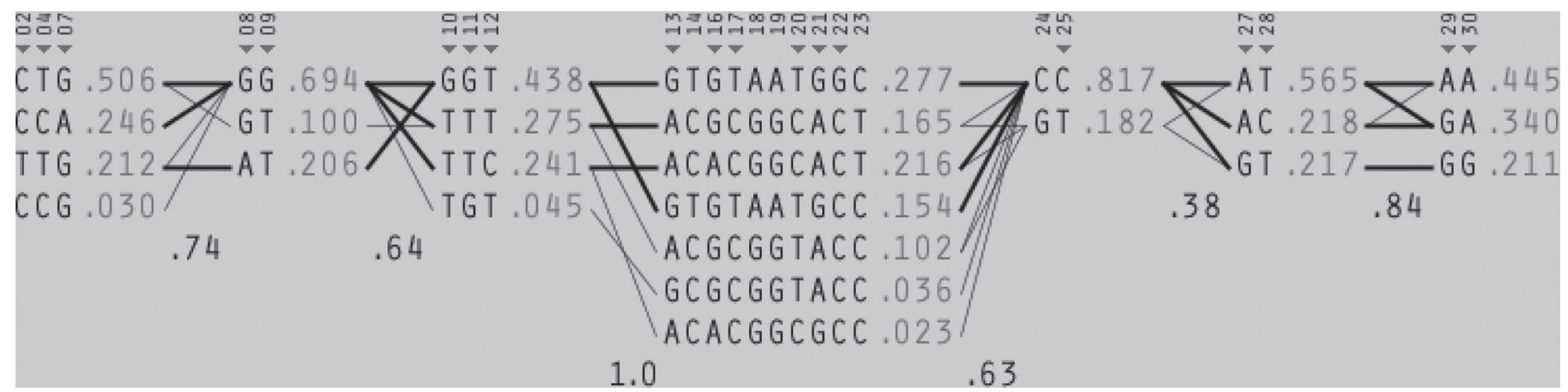

Figure 2. Haplotype blocks defined by the 31 SNP genotyped in the sheep GHR gene. Haplotype frequencies are reported near each haplotype within a block. For each crossing area, a value of multiallelic normalized coefficient of linkage disequilibrium $\left(\mathrm{D}^{\prime}\right)$ is given for the haplotypes displayed, representing the level of recombination between the 2 blocks. SNP: $2=$ rs $408890407,4=\operatorname{rs} 55631463,7=$ rs $405063669 ; 8=$ rs411154235, $9=\mathrm{rs} 404583153 ; 10=\mathrm{rs} 162153483,11=\mathrm{rs} 406893455,12=\mathrm{rs} 161146229 ; 13=\mathrm{rs} 161146242,14=\mathrm{rs} 407871250,16=\mathrm{rs} 415419991$, $17=\mathrm{rs} 409713530,18=\mathrm{rs} 425402906,19=\mathrm{rs} 161146298,20=\mathrm{rs} 426666828,21=\mathrm{rs} 430067568,22=\mathrm{rs} 412881843,23=\mathrm{rs} 400713333 ; 24=$

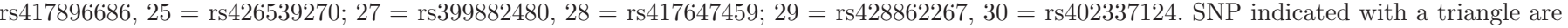
haplotype tagging SNP (htSNP). 
found that $I G F 1$ was polymorphic in some Italian dairy sheep breeds and showed a significant effect on milk lipid composition.

\section{CONCLUSIONS}

Several studies have highlighted an effect of $G H R$, GHRHR, and IGF1 on dairy traits in cattle, but information on a potential effect of the same genes on dairy traits in sheep was scarce. By genotyping 36 SNP distributed in GHR (31 SNP), GHRHR (2 SNP), and IGF1 (3 SNP) genes, in 380 Sarda sheep, our investigation has partially filled this gap. The polymorphism of GHR was associated with milk daily fat and protein yield (dFPY) and lactose and urea contents, whereas variability in IGF1 was associated with milk protein and casein contents. These findings may be useful for future breeding strategies based on implementing geneassisted selection.

\section{ACKNOWLEDGMENTS}

This research was funded by the Regione Autonoma della Sardegna (Cagliari, Italy; MIGLIOVIGENSAR CUP: B82I13000580002).

\section{REFERENCES}

Akers, R. M. 2002. Lactation and Mammary Gland. Iowa State University Press, Ames.

Baker, J., J. P. Liu, E. J. Robertson, and A. Efstratiadis. 1993. Role of insulin-like growth factors in embryonic and postnatal growth. Cell 75:73-82.

Banos, G., J. A. Woolliams, B. W. Woodward, A. B. Forbes, and M. P. Coffey. 2008. Impact of single nucleotide polymorphisms in leptin, leptin receptor, growth hormone receptor, and diacylglycerol acyltransferase (DGAT1) gene loci on milk production, feed, and body energy traits of UK dairy cows. J. Dairy Sci. 91:3190-3200.

Barrett, J. C., B. Fry, J. Maller, and M. J. Daly. 2005. Haploview: Analysis and visualization of LD and haplotype maps. Bioinformatics 21:263-265.

Bergan-Roller, H. E., and M. A. Sheridan. 2018. The growth hormone signaling system: insights into coordinating the anabolic and catabolic actions of growth hormone. Gen. Comp. Endocrinol. 258:119-133.

Bittante, G., C. Cipolat-Gotet, M. Pazzola, M. L. Dettori, G. M. Vacca, and A. Cecchinato. 2017. Genetic analysis of coagulation properties, curd firming modeling, milk yield, composition and acidity in Sarda dairy sheep. J. Dairy Sci. 100:385-394.

Blott, S., J.-J. Kim, S. Moisio, A. Schmidt-Küntzel, A. Cornet, P. Berzi, N. Cambisano, C. Ford, B. Grisart, D. Johnson, L. Karim, P. Simon, R. Snell, R. Spelman, J. Wong, J. Vilkki, M. Georges, F. Farnir, and W. Coppieters. 2003. Molecular dissection of a quantitative trait locus: A phenylalanine-to-tyrosine substitution in the transmembrane domain of the bovine growth hormone receptor is associated with a major effect on milk yield and composition. Genetics 163:253-266.

Bolormaa, S., B. J. Hayes, J. H. J. van der Werf, D. Pethick, M. E. Goddard, and H. D. Daetwyler. 2016. Detailed phenotyping identifies genes with pleiotropic effects on body composition. BMC Genomics 17:224. https://doi.org/10.1186/s12864-016-2538-0.
Brew, K., and R. L. Hill. 1975. Lactose biosynthesis. Rev. Physiol. Biochem. Pharmacol. 72:105-158.

Brooks, A. J., J. W. Wooh, K. A. Tunny, and M. Waters. 2008. Growth hormone receptor; mechanism of action. Int. J. Biochem. Cell Biol. 40:1984-1989

Chessa, S., I. J. Giambra, H. Brandt, A. M. Caroli, E. Gootwine, and G. Erhardt. 2017. Genetic diversity within economically important loci in European, Middle Eastern, and African sheep breeds: An insight into their development. Small Rumin. Res. 155:72-80.

Crisà, A., C. Marchitelli, L. Pariset, G. Contarini, F. Signorelli, F. Napolitano, G. Catillo, A. Valentini, and B. Moioli. 2010. Exploring polymorphisms and effects of candidate genes on milk fat quality in dairy sheep. J. Dairy Sci. 93:3834-3845.

Daly, M. J., J. D. Rioux, S. F. Schaffner, T. J. Hudson, and E. S. Lander. 2001. High-resolution haplotype structure in the human genome. Nat. Genet. 29:229-232.

Dettori, M. L., M. Pazzola, E. Pira, P. Paschino, and G. M. Vacca. 2015. The sheep growth hormone gene polymorphism and its effects on milk traits. J. Dairy Res. 82:169-176.

Di Stasio, L., G. Destefanis, A. Brugiapaglia, A. Albera, and A. Rolando. 2005. Polymorphism of the GHR gene in cattle and relationships with meat production and quality. Anim. Genet. 36:138-140.

Gabriel, S. B., S. F. Schaffnerv, H. Nguyen, J. M. Moore, J. Roy, B. Blumenstiel, J. Higgins, M. DeFelice, A. Lochner, M. Faggart, S. N. Liu-Cordero, C. Rotimi, A. Adeyemo, R. Cooper, R. Ward, E. S. Lander, M. J. Daly, and D. Altshuler. 2002. The structure of haplotype blocks in the human genome. Science 296:2225-2229.

García-Fernández, M., B. Gutierrez-Gil, J. P. Sanchez, J. A. Moran, E. Garcia-Gamez, L. Alvarez, and J. J. Arranz. 2011. The role of bovine causal genes underlying dairy traits in Spanish Churra sheep. Anim. Genet. 42:415-420.

Grochowska, E., B. Borys, P. Janiszewski, J. Knapik, and S. Mroczkowski. 2017. Effect of the IGF-I gene polymorphism on growth, body size, carcass and meat quality traits in Coloured Polish Merino sheep. Arch. Anim. Breed. 60:161-173. https://doi.org/10 $.5194 /$ aab-60-161-2017.

He, J. N., B. Y. Zhang, M. X. Chu, P. Q. Wang, T. Feng, G. L. Cao, R. Di, L. Fang, D. W. Huang, Q. Q. Tang, and N. Li. 2012. Polymorphism of insulin-like growth factor 1 gene and its association with litter size in Small Tail Han sheep. Mol. Biol. Rep. 39:9801-9807.

ISO-IDF (International Organization for Standardization and International Dairy Federation). 2006. Milk. Enumeration of somatic cells. Part 2: Guidance on the operation of fluoro-opto-electronic counters. International Standard ISO 13366-2 and IDF 148-2:2006. ISO, Geneva, Switzerland, and IDF, Brussels, Belgium

ISO-IDF (International Organization for Standardization and International Dairy Federation). 2013. Milk and liquid milk products. Determination of fat, protein, casein, lactose and $\mathrm{pH}$ content. International Standard ISO 9622 and IDF 141:2013. ISO, Geneva, Switzerland, and IDF, Brussels, Belgium.

Kim, S. H., and M. J. Park. 2017. Effects of growth hormone on glucose metabolism and insulin resistance in human. Ann. Pediatr. Endocrinol. Metab. 22:145-152.

Maj, A., M. Korczak, E. Bagnicka, L. Zwierzchowski, and M. Pierzchala. 2007. A TG-repeat polymorphism in the 5'-noncoding region of the goat growth hormone receptor gene and search for its association with milk production traits. Small Rumin. Res. 67:279-284.

Marques, M. R., I. C. Santos, N. Carolino, C. Belo, R. Renaville, and A. Cravador. 2006. Effect of genetic polymorphisms at the growth hormone gene on milk yield in Serra da Estrela sheep. J. Dairy Res. 73:394-405.

Møller, N., and J. O. L. Jørgensen. 2009. Effects of growth hormone on glucose, lipid, and protein metabolism in human subjects. Endocr. Rev. 30:152-177.

Pang, A. L. P., and W. Y. Chan. 2010. Molecular basis of diseases of the endocrine system. Pages 289-307, Chapter 22 in Essential Concepts in Molecular Pathology. W. B. Coleman and G. J. Tsongalis, ed. Academic Press, San Diego, CA.

Pazzola, M., M. L. Dettori, C. Cipolat-Gotet, A. Cecchinato, G. Bittante, and G. M. Vacca. 2014. Phenotypic factors affecting coagu- 
lation properties of milk from Sarda ewes. J. Dairy Sci. 97:72477257.

Pegolo, S., A. Cecchinato, M. Mele, G. Conte, S. Schiavon, and G. Bittante. 2016. Effects of candidate gene polymorphisms on the detailed fatty acids profile determined by gas chromatography in bovine milk. J. Dairy Sci. 99:4558-4573.

Roy, B., B. Brahma, S. Ghosh, P. K. Pankaj, and G. Mandal. 2011. Evaluation of milk urea concentration as useful indicator for dairy herd management: A review. Asian J. Anim. Vet. Adv. 6:1-19.

Sheridan, M. A. 2011. Hormonal control of reproduction and growth: Endocrinology of fish growth. Pages 1483-1489 in Encyclopedia of Fish Physiology: From Genome to Environment, Vol. 2. A. P. Farell, ed. Academic Press, San Diego, CA.

Vacca, G. M., M. L. Dettori, F. Balia, S. Luridiana, M. C. Mura, V. Carcangiu, and M. Pazzola. 2013. Sequence polymorphism at the growth hormone GH1/GH2-N and GH2-Z gene copies and their relationship with dairy traits in domestic sheep (Ovis aries). Mol. Biol. Rep. 40:5285-5294.

Vacca, G. M., M. Pazzola, M. L. Dettori, E. Pira, F. Malchiodi, C. Cipolat-Gotet, A. Cecchinato, and G. Bittante. 2015. Modeling of coagulation, curd firming and syneresis of milk from Sarda. J. Dairy Sci. 98:2245-2259.

Viitala, S., J. Szyda, S. Blott, N. Schulman, M. Lidauer, A. MakiTanila, M. Georges, and J. J. Vilkki. 2006. The role of the bovine growth hormone receptor and prolactin receptor genes in milk, fat and protein production in Finnish Ayrshire dairy cattle. Genetics 173:2151-2164.

Wang, H., L. Zhang, J. Cao, M. Wu, X. Ma, Z. Liu, L. Ruizao, Z Fuping, W. Caihong, and D. Lixin. 2015. Genome-wide specific selection in three domestic sheep breeds. PLoS One 10:e128688. 